\title{
Research on the Effects of Immobilizing the Nasal Region with a Thermoplastic Splint in Case of Patients who have Undergone Rhinoplasty
}

\begin{abstract}
CATALIN GHEORGHE BEJ INARIU'*, CARMEN GIUGLEA², SILVIU ADRIAN MARINESCU ${ }^{1}$
'Bagdasar-Arseni Emergency Clinical Hospital, Department of Plastic and Reconstructive Surgery, 12 Berceni Road, 041915, Bucharest, Romania

${ }^{2}$ Saint John Emergency Clinical Hospital, Department of Plastic and Reconstructive Surgery, 13 Vitan-Barzesti Road, 042122, Bucharest, Romania

The current study relates to the immobilization of the nasal region with splints using modern materials such as thermoplastic compounds in patients that have undergone rhinoplasty. The objectives of the research are to highlight the main characteristics of thermoplastic splints and to perform a comparative analysis in relation with traditional splints. The research was conducted on 2 batches, the first batch involving 24 patients that have undergone rhinoplasty, the postoperative immobilization being performed using metallic splints and the second batch involving 29 patients, thermoplastic splints being used for immobilization after the surgery. The results of the study are focused on evaluating both thermoplastic and traditional splints based on several criteria, such as modeling capacity, toxicity, surgical risks and patients' degree of satisfaction.
\end{abstract}

Keywords: nasal splint, thermoplastic materials, rhinoplasty, splints' modeling capacity

Complex nasal fractures pose a surgical dilemma for plastic surgeons community given the important aesthetic and functional roles of the nose. A change in splinting strategy may reduce the risk of the necessity of a secondary major surgery, discomfort and expenses for the patients [1].

The main characteristic that has been the basis for the increase of the popularity of the thermoplastic splints in medicine is represented by the ease of use, determined by the easy modeling while exposing the splint at high temperatures. Thermoplastic splints have a complex structure consisting of mixtures of polymers, their particularities being given by the nature of the chemical associations, as well as by the degree of cross-linking specific to each product. Depending on the chemical composition of the thermoplastic materials, their physical properties vary significantly, from the elastic structure (rubber like) to the reaching of complex plastic architectures characterized by low elasticity and high resistance to deformation. Polycaprolactone (PCL) $y=\left(\mathrm{C}_{6} \mathrm{H}_{10} \mathrm{O}_{2}\right)_{n}$ is one of the most popular polymers used for low temperature splinting materials (scheme 1 ).

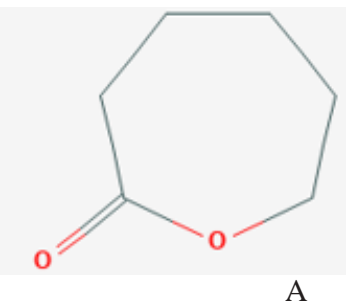

A

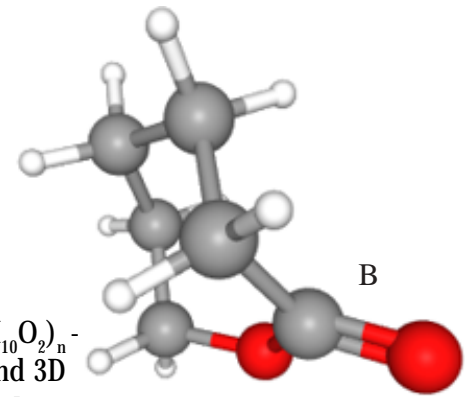

Scheme 1. Polycaprolactone $\left(\mathrm{C}_{6} \mathrm{H}_{10} \mathrm{O}_{2}\right)_{n}$
$2 \mathrm{D}$ graphic representation $(\mathrm{A})$ and $3 \mathrm{D}$ graphic representation (B) [4]

At the present time, an entire industry has been developed based on the use of thermoplastic materials, the fields of activity being extremely varied: constructions, automotive, electronics, petro-chemistry, consumer goods [2], as well as other fields of medicine such as orthopedics and dentistry. In orthopedics thermoplastic splints have been used in patients with different fractures, being successful and improving the radiological outcomes [3].

The applicability of thermoplastic principles in the medical field has been demonstrated for more than 30 years, the new generations of thermoplastic splints having really impressive properties, which practically define the standard in terms of postoperative immobilization. The results of the splinting processes are highly dependent on the materials used and the surgeon's skill [5]. Innovative and modern materials such as thermoplastics and advanced composites offer many advantages over the traditional materials, such as aluminum, wood or leather used since the 1980s [6].

The financial considerations were the basis of the existing reluctance in the developing countries regarding the introduction of thermoplastic materials into the medical routine, however the increase of the production capacity and the development of the infrastructure allowed to significantly reduce the costs of using these devices.

Rhinoplasty is required in most cases of nasal fractures, however early manipulation can lead to avoiding the surgery with an up to $50 \%$ risk of residual nasal deformities [7]. Preoperative consults, different surgical techniques, revisions and postoperative care are topics of interest that are being discussed by specialists [8-10]. Proper stabilization of the nasal grafts or bony components require postoperative monitoring and care in order to ensure healing. During the first weeks of recovery, the nasal shape of the tip and dorsum has to be protected with a splint [11]. In accordance with the specialized literature, the ideal splint should be light, adaptable, easy to remove and inexpensive [12]. The nasal splint involves molding and a plaster that should be used for at least 2 weeks using materials such as thermoplastic [13], fiberglass, metal or acrylic splints [14-16]. Despite the fact that the postoperative use of splints has been a widespread practice, surgical tape is still being considered as an alternative by plastic surgeons [17]. 
The surgical risks and the patients' degree of satisfaction are 2 of the most important aspects to be considered [18] when choosing the type of nasal splint.

The main objective of the research is to present the comparative analysis between the effects of using thermoplastic splints and traditional splints in patients that have undergone rhinoplasty.

The research objectives were represented by:

- Performing a comparative analysis of the postoperative results in case of using the 2 above-mentioned immobilization techniques;

- Evaluating the degree of patient satisfaction regarding the postoperative outcomes;

- Establishing the degree of feasibility of the 2 techniques, as evidenced by the questioning of the plastic surgeons involved in the research;

- Identifying the associated postoperative complications including hematoma formation, asymmetric edema, as well as the risk of conjunctivitis.

\section{Experimental part}

Materials and methods

The current study was conducted based on data analyzed between 2016 and 2019 involving 2 batches of patients undergoing a number of 53 surgical interventions:

- Batch I includes 24 patients (18 females and 6 males) in a protocol that involves the use of metal splints for the postoperative immobilization;

- Batch II includes 29 patients the sex ratio being 22:7 $(\mathrm{F}: \mathrm{M})$ in a protocol that involves the use of thermoplastic splints for the postoperative immobilization.

The inclusion criteria were represented by:

- Age between 18 and 55 years;

- Deformation of the skeletal bone (congenital or posttraumatic) (Figures 1 and 2);

- Modifications of the cartilaginous structures;

- Completion of the informed agreement regarding the surgical intervention and the study.

The exclusion criteria were represented by:

- Age under 18 or over 55;

- Systemic disorders that do not allow surgery (severe heart failure, chronic kidney failure);

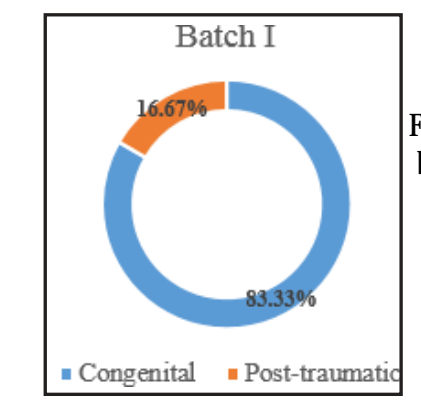

Fig. 1 Deformation of the skeletal bone in patients that underwent rhinoplasty followed by immobilization with a metal splint

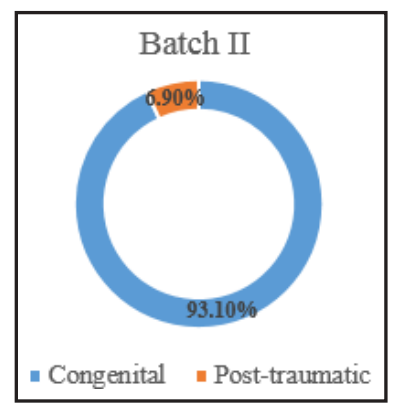

Fig. 2 Deformation of the skeletal bone in patients that underwent rhinoplasty followed by immobilization with a thermoplastic splint

- Psychiatric disorders with impact on patient's discernment;

- Improper psychological context.

\section{Protocol for applying the immobilization}

The modeling of the thermoplastic splints was performed according to the manufacturers' recommendations by immersing and keeping them in hot water $\left(70-75^{\circ} \mathrm{C}\right)$, for $3-5$ minutes, followed by drying with a cloth; afterwards, the splint was applied at the level of the nasal region and modeled according to the particular needs of the case. Maintenance of the position is ensured in most cases by the existence of an internal adhesive layer.

In the case of the use of metallic splints (aluminum), the immobilization was applied after the flexible contention was achieved by the use of Omnistrip adhesive strips. The modeling of the metallic splint was realized by applying digital pressure at the level of the alar extremities of the splint, followed in selected cases by the use of a median conformer. Maintenance of the position is ensured in most cases by the existence of an internal adhesive layer.

\section{Results and discussions}

The research was conducted based on several criteria considered in order to determine the main advantages and disadvantages of the 2 types of splints (Table 1 ).

Following the comparative analysis, the research result show that the thermoplastic splint have multiple advantages compared to the metallic splints, the most significant of which are:

- The increased modeling capacity that allows the surgeon to immobilize the nasal region in the ideal position, without the risk of hidden areas due to the lack of contact between the splint and the tegument;

- Maintaining the shape, the exerted pressure and the full contact with the skin reduces the rate of occurrence of postoperative hematomas;

- Decreased surgical risks due to the increased modeling and remodeling capacity in case of a procedure error;

\begin{tabular}{|c|c|c|c|}
\hline $\begin{array}{l}\text { No. } \\
\text { crt. }\end{array}$ & Analyzed criteria & Thermoplastic & Traditional \\
\hline 1. & Modeling capacity & High & Limited \\
\hline-2 & Toxicity & $-\cdots-$ Low $^{-}$ & Moderate \\
\hline-3 & Surgical risks & Low & Moderate \\
\hline 4 & Postoperative complications & Reduced risks & $\begin{array}{l}\text { Moderate risks of } \\
\text { complications such as } \\
\text { hematoma, conjunctivitis }\end{array}$ \\
\hline 5 & $\begin{array}{l}\text { Postoperative aesthetic } \\
\text { results }\end{array}$ & Reduced risk of asymmetry & Risk of asymmetry \\
\hline
\end{tabular}

Table 1

COMPARISON BETWEEN THERMOPLASTIC AND TRADITIONAL SPLINTS AFTER RHINOPLASTY 


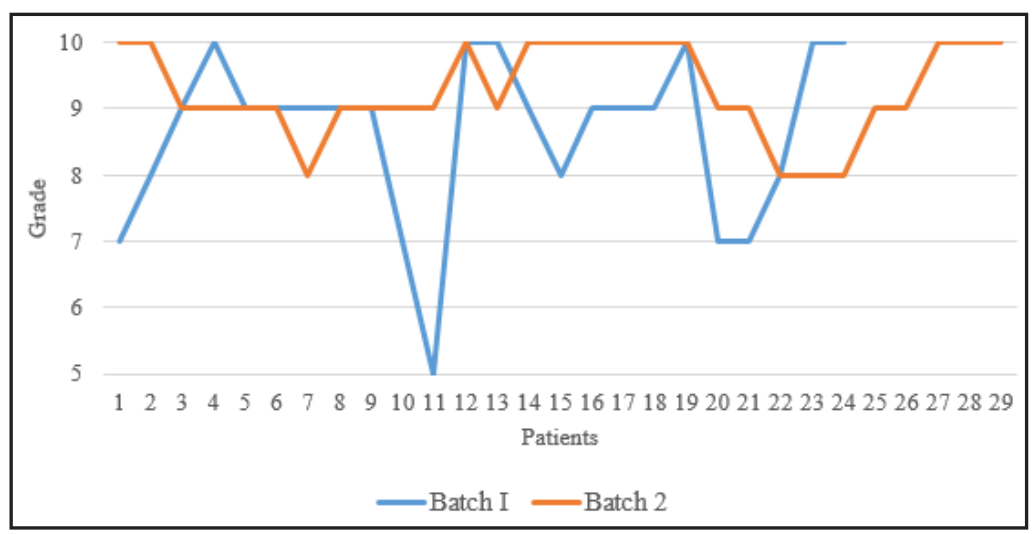

Fig. 3 Patients' degree of satisfactions in Batch I and Batch II

- The increased contact surface between the splint and the tegument significantly reduces the risk of asymmetric edema;

- The capacity of remodeling during the postoperative period, with the preservation of the physico-chemical and structural properties;

- The use of thermoplastic splints reduces the risk of conjunctivitis occurring by immobilization through a metal splint due to the lack of mobile fragments that could cause irritant conjunctivitis;

- Medical device with a high degree of safety in the case of postoperative facial trauma.

The newest generation of thermoplastic splints also has the advantages of X-ray permeability, an extremely important element for patients who have suffered complex traumas of the facial region, which involves comminuted fractures of the nasal, zygomatic and maxillary bone regions [19].

The lack of toxicity of the polymers used to make the thermoplastic splints is also an important advantage of this type of splint, considering the general international concerns about avoiding the use of chemical materials with potential pollutants [20]. Without a doubt the ability to make thermoplastic splints from biodegradable compounds has been an extremely important step in the development of the latest product classes.

The patients' degree of satisfaction related to the aesthetic and functional postoperative results was measured, the patients appreciating the results with a grade from 1 to 10 , the highest score being 10 (Figure 3).

The average degree of satisfaction was higher (9.28; Standard deviation $(S D)=0.7$ ) in case of using thermoplastic splints compared to traditional splints (8.63; $\mathrm{SD}=1.28$ ). Regarding the surgeons' experience using the thermoplastic splint, the average grade for thermoplastic splints was $8.5(S D=1.14)$ and $7.72(S D=1.07)$ for traditional splints.

\section{Conclusions}

The comparative analysis with metallic splints shows that the thermoplastic splints are chemically stable and odorless products that offer many benefits both for the patients and the plastic surgeons.

The immobilization of the nasal region is a very important stage during the surgical protocol for rhinoplasty. Achieving the fixation of the bone and cartilaginous structures exerts a major impact on the aesthetic aspect, contributing to the improvement of the respiratory function. In this context, the technique of immobilization by thermoplastic splint offers a series of advantages compared to the classic immobilization techniques. The increased modeling capacity, the decreased risk of adverse reactions and the quality-price-ratio are elements that may define thermoplastic splints as the gold standard for the immobilization of the nasal region.

\section{References}

1.J OSHI, S.J ., MISHRA, G., PANCHAL, N.K., European J ournal of Plastic Surgery, 39, nr. 2, 2016, p. 85.

2.TABACU, S., HADAR, A., MARINESCU, D., MARIN, D., DINU, G., IONESCU, D.S, Mat.Plast., 45, no. 1, 2008, p. 113.

3.VIDAL, P., BERNER, J.E., Plast Reconstr Surg Glob Open, 4, nr. 12, 2016, p. 1188

4.*** U.S. NATIONAL LIBRARY OF MEDICINE, [online] https:// pubchem.ncbi.nlm.nih.gov/ compound/Caprolactone [Accessed 01.08.2019].

5.*** U.S. NATIONAL LIBRARY OF

6.KHUDAIRY, A.A., HIRPARA, K.M., KELLY, I.P., QUINLAN, J .F., European J ournal of Orthopaedic Surgery \& Traumatology, 23, nr. 6, 2012, p. 647. 7.LI, J., TANAKA, H., 3D Printing in Medicine, 4, nr. 5, 2018.

8.TAGHIZADEH, R., LEWIS, C.J., STEVENSON, S. BARNARD, A., ERDMANN, M., European J ournal of Plastic Surgery, 39, nr. 7, 2016, p. 7.

9.BURSTEIN, F.D., Cosmetic Surgery, 2012, p. 249.

10.GRIGORYANTS, V., BARONI, A., Aesthetic Plastic Surgery, 37, nr. 3, 2013, p. 516.

11.BEJINARIU, C.G., MARINESCU, S.A., ENESCU, M.D., Modern Medicine, 26(1), 2019, p. 17.

12.KANKAYA, Y., ORUÇ, M., GURSOY, K., KOCER, U., Aesthetic Plast Surg, 2014, 38, nr. 4, p. 825.

13.SHETTY, V., VASISHTA, S.M.S., MAXILLOFAC, J., Oral Surgery, nr. 12, 2013, p. 348.

14.BESNEA, D., DINU, E., MORARU, E., SPANU, A., RIZESCU, C., CONSTANTIN, V., Mat.Plast., 56, no. 1, 2019, 167.

15.PERSICHETTI, P., SIMONE, P., TENNA, S., MARANGI, G.F., DI LELLA, F., CAGLI, B., LI VECCHI, G., Plast Reconstr Surg, 113, nr. 6, 2004, p. 1891.

16.AHN, M.S., MAAS, C.S., MONHIAN, N., Arch Facial Plast Surg, 5, nr. 2 , 2003, p.189.

17.SHETTY, V., VASISHTA, S.M., J Maxillofac Oral Surg, 12, nr. 3, 2013, p.348.

18.COOMBES, A.G.A., GREENWOOD, C.D., SHORTER, J.J., Plastic Materials for External Prostheses and Orthoses. In: WISE, D.L., TRANTOLO, D.J., ALTOBELLI, D.E., YASZEMSKI, M.J., GRESSER, J.D. Human Biomaterials Applications. Humana Press, Totowa, NJ , 1996. 19.MARINESCU, S.A., BEJ INARIU, C.G., BADEANA, A., TANASESCUCIUVICA, S., ENESCU, D.M., Rev.Chim.(Bucharest),70, no. 4, 2019, p. 1234.

20.URECHESCU, H., PRICOP, M., PRICOP, C., MATEAS, M., NATANAEL, S., GALATANU, S.V., Mat.Plast., 54, no. 3, 2017, p. 477.

21.MARINESCU, S., BEJINARIU, C.G., GIUGLEA C., Mat.Plast., 56, no. 1, 2019, p. 229.

Manuscript received: 20.07.2019 